\title{
Implantación y evolución de la encomienda en la provincia de Tabasco, 1522-1625
}

\author{
Francisco L. Jiménez Abollado \\ Seminario de Antropología Americana \\ Universidad de Sevilla
}

\begin{abstract}
El presente trabajo intenta analizar la evolución de una institución como la encomienda en la Provincia de Tabasco, desde su implantación en 1522 hasta el primer cuarto del siglo XVII. Se hace hincapié en la importancia de dicha institución la de mayor atractivo socio-económico para la escasa población española asentada en la provincia, debido al carácter fronterizo y marginal de la misma, y a la escasez de otros incentivos económicos. Asimismo, se examinan algunos aspectos como la incorporación de pueblos a la Real Corona y la política de "ayudas de costa", como fuentes de compensación para aquellos pobladores y descendientes de conquistadores que no poseían encomiendas.
\end{abstract}

La institución de la encomienda, introducida en las Indias desde los primeros años de la presencia hispana y regulada posteriormente por la Corona, era el premio que los conquistadores y sus descendientes exigían por los servicios prestados. A través de dicho sistema se ordenaba el repartimiento de indios, que tenían que entregar cierta cantidad de tributo convenido en una tasación al encomendero. ${ }^{1}$ La encomienda cumplía la función de ser, en cierta medida, el sustento económico de la población española, pero también, como destaca Salvador Rodríguez Becerra, ofrecía la posibilidad al encomendero de realizarse y ser tenido como un señor de vasallos. ${ }^{2}$ A cambio del pago del tributo el encomendero tenía la responsabilidad de instruir cristianamente a sus indios, lo cual implicaba la presencia de un clérigo residente o itinerante que proveyera dicha instrucción, así como la obligación de la defensa de la tierra. ${ }^{3}$ Señala Elías Zamora Acosta que la introducción de la encomienda sirvió para la explotación de los pueblos conquistados, además de ser un elemento primordial para la aculturación de los indígenas, especialmente en el aspecto religioso. ${ }^{4}$

\footnotetext{
1 Referencia obligada para el estudio de la encomienda en Indias es la obra de Zavala, Silvio: La encomienda indiana, México, 1973.

2 Rodríguez Becerra, Salvador: Economía y conquista. Los inicios de la colonización en Guatemala, Sevilla, 1977, pág. 48.

3 Recopilación de Leyes de los Reynos de Indias, libro VI, título IX, leyes 1-4.

4 Zamora Acosta, Elías: Los mayas de las Tierras Altas en el siglo XVI, Sevilla, 1985, pág. 247.
} 
La introducción del sistema de encomiendas en Tabasco ${ }^{5}$ se sitúa en torno a 1522, cuando Gonzalo de Sandoval hizo el primer reparto de indios entre los conquistadores que le acompañaban en su expedición hacia el sureste de la Nueva España:

“... repartió Sandoval aquellas provincias y pueblos en nosotros, después de las haber enviado a visitar e hacer la división de la tierra y ver las calidades de todas las poblaciones."

Desde la villa de Espíritu Santo, en Coatzacoalcos - convertida en cabeza de puente de las entradas que se debían de realizar en Tabasco y Chiapas, y asentamiento de buena parte de los veteranos soldados que habían participado en la conquista de Tenochtitlan-, los conquistadores podrían asistir a los pueblos y tierras que les fueron adjudicadas en sus respectivos repartimientos. En Tabasco, los primeros pueblos que se encomendaron fueron los indios de la Chontalpa (Copilco y Cimatán), así como los enclavados en la región zoque, debido a que se encontraban en el derrotero que conducía a la vecina región de Chiapas, otro objetivo fijado por los conquistadores asentados en la villa de Espírutu Santo.

Este primer reparto de pueblos fue más nominal que real debido a la inseguridad del territorio y a la escasa presencia española en el mismo, unidas a las constantes negativas de los indígenas a pagar unos tributos que consideraban onerosos y que, a veces, terminaban en levantamientos, como los que hubo en Cimatán y Copilco. ${ }^{7}$

La documentación sobre esta primera etapa de la encomienda es muy escasa. Uno de los primeros encomenderos que obtuvieron repartimiento de indios en Tabasco fue el soldado-cronista Bernal Díaz del Castillo. Sus relaciones de méritos y servicios así lo atestiguan:

"Por la presente deposito en vos Bernal Díaz del Castillo vecino de la villa del Espíritu Santo los señores y naturales de los pueblos de Teapa y Potuchan que son en la provincia de Comatan (Cimatán) para que os sirváis de ellos y los hayáis de enco-

5 Peter Gerhard, en su obra La frontera sureste de la Nueva España, México, 1991, pág. 30, confecciona un breve e interesante análisis sobre diversas fuentes documentales y bibliográficas relativas a la encomienda en Tabasco.

6 Díaz del Castillo, Bernal: Historia verdadera de la conquista de la Nueva España, Madrid, 1982, vol. I, pág. 437.

7 Ibídem. 
mienda y os ayuden en vuestras haciendas y granjerías... hecha a veinte de setiembre de mil quinientos veinte y dos años. Hernando Cortés". 8

Como él, fueron muchos los conquistadores que accedieron al repartimiento de indios en Tabasco. Tal era el caso de Miguel Sánchez Gascón, que recibió de Cortés, en la misma fecha que Bernal Díaz, la mitad de los pueblos de Cimatán, Ostuacan, Ayapa y Huaimango. ${ }^{9}$ Desafortunadamente carecemos de fuentes documentales que puedan acreditarnos el número de encomiendas y los encomenderos que recibieron repartimientos en Tabasco durante estos primeros años de presencia española.

Muchos de estos nuevos pobladores, en años posteriores, durante los gobiernos interinos de Marcos de Aguilar y Alonso de Estrada en Nueva España, siguieron percibiendo repartimientos de indios en Tabasco, Chiapas y Oaxaca, áreas adyacentes a la villa del Espíritu Santo:

“... Marcos de Aguilar me depositó otro pueblo que se dice Chamula que en aquella sazón asimismo era término del dicho Guazacualco y el tesorero Alonso de Estrada me depositó estancias (Mazateupa, Xalpanecas y Tapocingo) los cuales dichos pueblos poseí sin contradicción ninguna......10

La llegada en 1527 a la alcaldía mayor de la provincia de Tabasco del capitán Baltasar Osorio y del capitán Diego de Mazariegos a Chiapas, afectó negativamente al régimen de encomiendas de estos primeros pobladores. El paulatino poblamiento de las villas de Santa María de la Victoria y de Ciudad Real de Chiapas y las dificultades que suponía el mantenimiento de sus habitantes, movieron al gobierno interino de la Nueva España a que se desposeyeran las encomiendas que estaban en poder de los vecinos residentes en Espíritu Santo y que se pusieran en los términos de las dichas villas y sus habitantes.

8 Archivo General de Indias (en adelante, AGI), Patronato, 87, n. ${ }^{\circ}$ 1, r. 2, Doña Marina Ramírez de Vargas, viuda de Juan Becerra del Castillo, como madre curadora de doña María de Cepeda, su hija, presenta información de los méritos y servicios del capitán Gaspar de Cepeda, Gómez Díaz de la Reguera y Alonso Ramírez de Vargas, padre, abuelo y bisabuelo de la susodicha y de los de Bernal Díaz del Castillo y Bartolomé Becerra, padre y abuelo de Juan Becerra, Guatemala, 13 de junio de 1619.

9 AGI, México, 203, doc. 27, Informaciones de oficio y parte: Miguel Sánchez Gascón, fundador y poblador de la villa de Chiapa y Tabasco, vecino de Espíritu Santo, Villa de Espírutu Santo, 1537; Zavala: La encomienda..., pág. 322.

10 AGI, Patronato, 87, n. ${ }^{\circ}$ 1, r. 2, Doña Marina Ramírez de Vargas, ... presenta información de los méritos y servicios del capitán Gaspar de Cepeda, Gómez Díaz de la Reguera y Alonso Ramírez de Vargas, ... Guatemala, 13 de junio de 1619. 
Muchos de los vecinos de Espíritu Santo que vieron perder sus repartimientos en beneficio de las villas de Tabasco y Chiapas y sus nuevos pobladores, iniciaron una batalla legal para que les dieran "en recompensa otros pueblos como aquellos, para que se aproveche de ellos por el tiempo que fuere la voluntad de S.M....". Algunos, al cabo de los años, recibieron sus compensaciones, como sucedió con Bernal Díaz:

“...le diereis un corregimiento en esa dicha provincia de Guatemala... y ciertas fes de encomienda de indios de los pueblos de Sacatepeque y Juanagazapa y el pueblo de Misten....'.12

Con la llegada del capitán Baltasar Osorio, máxima autoridad en la provincia de Tabasco por el poder que le otorgó el gobernador Alonso de Estrada, se quiso levantar los cimientos para un decisivo asentamiento de la población española en la villa de Santa María de la Victoria. Un primer paso para su consecución fue el cambio de las encomiendas de los antiguos conquistadores de Espíritu Santo a manos de los nuevos pobladores asentados en la villa.

Pero conociendo las asperezas y dificultades geográficas y, por ello, la complicada incorporación de las distintas comunidades indígenas al régimen colonial, no era extraño que la situación fuera caótica para la mayoría de los nuevos pobladores, surgiendo rápidamente los disentimientos y las quejas. Las continuas lluvias y el angosto y difícil régimen fluvial, propios de un clima tropical húmedo, eran un impedimento para los encomenderos a la hora de asistir a sus repartimientos, lo cual fue aprovechado por muchos pueblos de indios para alzarse de nuevo o negarse a acudir a la villa para entregar los tributos. Estas pésimas condiciones de vida condujeron a vecinos y encomenderos a plantearse muy seriamente abandonar la provincia, y a las autoridades, a pedir auxilio a la Audiencia de México. Fueron estas causas las que motivaron, en primer lugar, la destitución de Baltasar Osorio y, con posterioridad, la confianza en el adelantado Francisco de Montejo, que fue nombrado alcalde mayor de la provincia de Tabasco en 1529. En 1533 la Corona lo nombró gobernador de la región comprendida entre el río Copilco y el río Ulúa.

A partir de este momento y hasta 1549 — cuando mediante una real cédula de junio de dicho año el rey decidió que todas las encomiendas per-

11 Ibídem.

12 Ibídem. 
tenecientes a los Montejo fuesen removidas y pasaran a la Corona-,$^{13}$ la historia de la provincia de Tabasco quedaría unida a esta familia. Un amplio sector de los vecinos asentados en la villa de la Victoria seguidores de la política ejercida por los Montejo, reconocía que éstos facilitaron seguridad a la escasa población española y establecieron el sistema de encomiendas de forma definitiva. Sin embargo, no se pudo evitar ciertos problemas en el disfrute de algunas de ellas. Los principales afectados fueron algunos pobladores adeptos a la anterior máxima autoridad de la provincia, Baltasar Osorio. Los casos de dos de ellos, Bernardino de Medina y Baltasar de Gallegos, aparecen recogidos documentalmente. Medina, que pasó a Tabasco en compañía de Baltasar Osorio, recibió en encomienda los indios de Ocelotlan y Tacotalpa; y del adelantado Francisco de Montejo, por haber participado en la conquista y pacificación de la provincia, el pueblo de Silosuchiapa y la mitad de Spinzol. ${ }^{14}$ Sin embargo, aprovechando su estancia durante algunos años en la capital del virreinato, Francisco de Montejo el sobrino le separó de sus encomiendas, que pasaron a su propiedad.

Por su parte, Baltasar de Gallegos, que también participó en la pacificación de Tabasco en la hueste de Baltasar Osorio, recibió en encomienda, por el poder de Alonso de Estrada, los pueblos de Tabasco, Tamulte, Gueyecaque (Oxiacaque), Campango (Huaimango) y Anta. ${ }^{15}$ Aprovechando la marcha de Gallegos a España, donde había acudido para casarse, el adelantado Montejo le apartó de sus indios y encomiendas, entregándoselos a su hijo Francisco de Montejo. Gallegos se defendió de esta separación aduciendo que, cuando partió a Castilla, "dejó en los dichos pueblos sus calpisques para que tuviesen cuidado de industriar los indios en las cosas de la Santa Fe católica y se recogiese los tributos de los dichos indios....". ${ }^{16}$

Hasta la deposición del adelantado Montejo del gobierno de Yucatán en 1549 y, por ende, la remoción de sus encomiendas y las de su familia en la Corona, el poder arbitrario, manipulador y nepótico, fue el eje de su política en relación con las encomiendas. Fue acusado por religiosos y antiguos conquistadores de apropiarse para él, su familia y paniaguados, de las enco-

13 AGI, México, 2.999, Real cédula al licenciado Santillán, oidor de la Audiencia de México, 17 de junio de 1549 .

14 Rubio Mañé, J. Ignacio: Archivo de la Historia de Yucatán, Campeche y Tabasco, México, 1942, vol. I, págs. 3-36; Civeira Taboada, Miguel: Tacotalpa, capital de Tabasco de 1666 a 1795, Villahermosa, Tab. México, 1973, págs. 9-25.

15 AGI, México, 204, doc. 2, Información de los servicios de Baltasar de Gallegos, natural de la ciudad de Sevilla y residente en México para pedir mercedes, 1545.

16 Ibídem. 
miendas de más valor. Como se ha visto con anterioridad, ni el adelantado ni sus familiares pusieron cortapisa alguna a la hora de remover y privar de encomiendas a cualquier persona que pudiera ser para ellos un obstáculo.

La encomienda significaba para los soldados y conquistadores que iniciaban una nueva etapa como pobladores —en un área cuyo incentivo más seguro era el tributo de cacao que se exigía a los indígenas, al no haber metales preciosos ni otros estímulos económicos-, un premio que podía compensar el esfuerzo y el riesgo de una pacificación laboriosa y dividida en diversas fases como fue la de Tabasco. Montejo el mozo, así como su primo Montejo el sobrino, siguiendo las instrucciones del adelantado, fueron implantando, gradualmente, el sistema de encomiendas en la provincia.

Sin embargo, durante estos primeros años de presencia española, con una paz inestable en todo el territorio de la provincia de Tabasco - especialmente a lo largo de la frontera serrana de Chiapas y algunos pueblos próximos a Santa María de la Victoria-, había una renuencia manifiesta en aquellos pueblos a servir a sus encomenderos. Las excesivas demandas y el duro tratamiento a los indígenas venían provocados porque aún no se había fijado una tasación oficial de los tributos y servicios que debían dar a sus encomenderos. Otro factor de descontento venía motivado por la presencia de calpisques en los pueblos encomendados que se dedicaban a exigir dichos tributos y servicios. Según Chamberlain, estos calpisques eran de facto jefes de los pueblos donde trabajaban y sus actos autoritarios se añadían a las ofensas que sufrían los indígenas. ${ }^{17}$

La encomienda, en esta época previa a la implantación de las Leyes Nuevas, era la única forma de recompensa de buena parte de aquellos conquistadores y soldados que habían participado en la sujeción de la provincia de Tabasco. Las difíciles y especiales condiciones geográficas y climáticas, la falta de otros incentivos económicos y la limitada posibilidad para el comercio, unidas a las características culturales del área —escasa densidad de población, poblamiento disperso y belicosidad de los indios-, hacían de la encomienda la única atracción económica y social de los escasos pobladores que se atrevían a instalarse en la villa de Santa María de la Victoria.

Con anterioridad a la promulgación de las Leyes Nuevas (1542) los indios de Tabasco, al igual que los del resto de los territorios hispanos, carecían de un marco jurídico que reglamentara los deberes y derechos de

17 Chamberlain, Robert S.: The governorship of the Adelantado Francisco de Montejo in Chiapas, 1539-1544, Washington, 1948, págs. 190-197. 
los encomenderos y encomendados. Señala Silvio Zavala que en los debates previos a estas leyes "se daba por aceptada la libertad del indio y se procuraba hallar la fórmula jurídica que, sin desconocer esta premisa, fuera capaz de satisfacer las necesidades económicas de los particulares españoles". ${ }^{18}$ La encomienda en estos años se convirtió en un bien comerciable, donde el poseedor de la misma adquiría el derecho de vender, trocar o intercambiar. El propio Montejo había autorizado estas prácticas reñidas con las disposiciones reales que la Corona y el Consejo de Indias habían dictado para proteger al indígena. Claros ejemplos de estas irregularidades eran las que realizó Alonso López, cuñado, representante del adelantado en Tabasco y visitador general de la provincia, como poseedor de varias encomiendas - Tamulte, Huaymango, Soyataco y Nacaxuxuca-, que actuó de forma anómala ordenando y exigiendo a sus indios encomendados que dieren de tributo más de lo que estaba señalado:

"Pedro Gaitán regidor, dice que vio en el pueblo de Nacaxuxuca que es de Alonso López le dio 60 xiquipiles soliendo no dar más de 20 en sesenta días, y en el pueblo de Huaymango... le dieron otros 60 xiquipiles y solían dar 20, y que el pueblo de Soyataco, que es también de Alonso López en depósito le dio otros 25 xiquipiles o 30, soliendo no dar más de 10 en sesenta días, y en el pueblo de Tamulte que el dicho Alonso López tenía a su cargo por Don Francisco, hijo del Adelantado Montejo, les sacó también tributos...”. ${ }^{19}$

La promulgación de las Leyes Nuevas afectó profundamente al sistema de las encomiendas en las Indias. Las posteriores reformas a dichas disposiciones, especialmente las referidas a la duración de las encomiendas, así como el fin y objeto que se propuso la Corona con respecto a esta institución — supresión de la jurisdicción del encomendero sobre los indios y la limitación al goce del tributo en vez de las antiguas prestaciones personales-, buscaban aunar los deseos de los encomenderos por mantener su estatus y de la Corona por encauzar, controlar y evitar los abusos de las encomiendas.

La aplicación de las Leyes Nuevas en los territorios administrados por el adelantado Montejo y sus más allegados familiares no llegó a hacerse efectiva hasta finales de la década de 1540. El que buena parte del área se

18 Zavala: La encomienda..., pág. 73.

19 AGI, Justicia, 195, Los fiscales, licenciados Cristóbal de Benavente y Juan de Villalobos contra Alonso López, vecino de la villa de Santa María de la Victoria, provincia de Tabasco y en su nombre Francisco Ramírez y Sebastián Rodríguez, 1541-1545. Un xiquipil equivalía a 8.000 almendras de cacao. 
encontrara todavía en esos momentos en la fase final del proceso conquistador y pendiente de posibles levantamientos a lo largo y ancho de la gobernación, motivó esos retrasos en la imposición de dicho cuerpo legal.

La primera tasación oficial efectuada en Tabasco fue la que, en 1549, realizó el presidente de la Audiencia de los Confines, López de Cerrato, desconocedor entonces que, desde un año antes, la Corona había establecido que tanto Tabasco como Yucatán habían pasado a depender de la Audiencia de México. Esta tasación, que originalmente habían elaborado Montejo y los franciscanos, estaba impregnada en buena parte del espíritu y de los contenidos de las Leyes Nuevas, pues en el fondo intentaba controlar el poder de los encomenderos. ${ }^{20}$ Sin embargo, como señala Cristina García Bernal, esta tasación "conserva reminiscencias de la primera época, al mantener como parte integrante de la tasación el trabajo de un determinado número de indios para el servicio doméstico del encomendero". ${ }^{21}$ Así, concretamente, en los ocho pueblos tasados en la provincia de Tabasco en 1549, los indios de servicio puestos entre los encomenderos asentados en la villa de Santa María de la Victoria se elevaban a $22 .{ }^{22}$ Hubo que esperar a 1552, cuando el oidor Tomás López visitó la gobernación de Yucatán para proceder a modificar las tasaciones de 1549 y a la supresión del servicio personal de los indios a los encomenderos, conmutándose con otras prestaciones. ${ }^{23}$

Entre la visita que Alonso López llevó a cabo en 1541 y las tasaciones efectuadas por el licenciado Cerrato en 1549, contabilizamos un total de 30 encomiendas en la provincia de Tabasco. ${ }^{24}$ De ellas, cuatro estaban en manos de Francisco de Montejo el sobrino, precisamente las que tenían más indios y las que tributaban mayor cantidad de cacao, entre otros productos: Tacotalpa, Tecomaxiaca, Ocelotlan y Xicalango. El resto se encontraba puesta en antiguos conquistadores y pobladores, muchos de ellos afectos al adelantado y, en una menor cantidad, en la Real Corona.

20 Ver González Cícero, Stella María: Perspectiva religiosa en Yucatán. 1517-1571, México, 1978, págs. 134-136.

21 García Bernal, Manuela Cristina: Población y encomienda en Yucatán bajo los Austrias, Sevilla, 1978, págs. 198-199.

22 AGI, Guatemala, 128, Tasaciones de la villa de la Victoria de la provincia de Tabasco que es junto a Yucatán, 1549, fols. 397-401; Paso y Troncoso, Francisco del: Epistolario de la Nueva España, 1505-1818, México, 1939-1942, vol. VII, págs. 107-112; Zavala: La encomienda..., págs. 469-471.

23 Zavala: La encomienda..., págs. 619-620; Jiménez Núñez, Alfredo: "Política española y estructuras indígenas: el área maya en el siglo XVI", Revista de la Universidad Complutense, vol. XXVII, núm. 117, Madrid, 1980, págs. 137-138.

24 AGI, Justicia, 195, Visitación de la provincia de Tabasco hecha por Alonso López, 24 de enero de 1541 , fols. 634 y ss. 
Como se ha señalado con anterioridad, una real cédula de junio de 1549 ordenaba que se desposeyera de sus encomiendas al adelantado Francisco de Montejo y que éstas fueran incorporadas a la Real Corona. ${ }^{25}$ Las causas de esta privación, aparte de las motivadas por su actuación política, considerada arbitraria, criticada tanto por los religiosos franciscanos como por los conquistadores y pobladores no afectos al adelantado, estaban en la aplicación de las Leyes Nuevas, que ordenaban que tanto los virreyes como los gobernadores, el resto de autoridades políticas, judiciales y eclesiásticas, no pudiesen disponer de indios ni encomiendas. Prohibición ésta que se ampliaba a sus familiares más directos.

En 1546 la Corona criticaba la actuación de la Audiencia de los Confines, que consideraba lícita la permanencia de las encomiendas de los gobernadores si éstas estaban puestas en cabeza de sus mujeres e hijos antes de que se publicaran las Leyes Nuevas:

“...estoy maravillado de vosotros haber disimulado con esto porque como tenéis entendido la voluntad de S.M. es que de ninguna manera ni por ninguna vía ningún gobernador tenga indios encomendados y así está mandado por las dichas Nuevas Leyes y tenerlos sus mujeres e hijos es un fraude de ellos...". ${ }^{26}$

Argumentaba la Corona que las mujeres e hijos de gobernadores y demás cargos públicos no podían tener encomiendas, pues a ellos les faltaban razones por las que dichas remuneraciones se permitieron. Así, las mujeres no podían defender la tierra, ni tener ni usar armas y caballos para su defensa:

“... y las mismas razones hay en los hijos de los gobernadores que están debajo de su poder porque no tienen casa poblada ni defienden la tierra y en efecto es tenerlos sus padres y no ellos...". ${ }^{27}$

La legislación solamente salvaguardaba aquellas encomiendas que estaban puestas en los hijos varones que estuvieran casados e hiciesen vida independiente y las disfrutaran desde que estaban en tal estado civil. ${ }^{28}$

Coincidimos con García Bernal cuando señala que la cédula de 1549 ratificaba la aspiración de la Corona por poner la Gobernación de Yucatán

25 AGI, México, 2.999, Real cédula al licenciado Santillán, oidor de la Audiencia de México, 17 de junio de 1549 .

26 AGI, México, 99, doc. 3, Copia de un cargo que escribió a la Audiencia de los Confines, Audiencia de los Confines, 9 de julio de 1546.

27 Ibídem.

28 Ibídem. 
—donde se incluía Tabasco- bajo el dominio directo del poder real. ${ }^{29} \mathrm{El}$ adelantado Montejo tuvo que someterse a una investigación realizada por la Audiencia de los Confines sobre los tributos y rentas que percibió, ilegalmente, de sus encomiendas desde la promulgación de las Leyes Nuevas hasta la privación de las mismas encomiendas. En este período de cuatro años, según el juez de comisión de dicha información Francisco de Ugalde, "debe el dicho adelantado a S.M. todas las rentas y tributos de los pueblos de los repartimientos que él y su mujer e hijos y entenados y nietos tuvieron... porque por dolo y cautelas del dicho adelantado se dejó de ejecutar y se estuvo con ellos, los cuales dichos repartimientos eran de Yucatán, Tabasco, Guazacualco, Honduras". ${ }^{30}$

Con anterioridad, en 1547, también por mandato de la Audiencia Real de los Confines, mediante unas provisiones reales, se notificó a Montejo que no tuviesen indios él, su mujer y su hijo en las provincias de Yucatán y Tabasco. Además, se le desposeyó de la alcaldía mayor de la provincia, adonde no asistía desde 1535, dirigiéndola a través de personas interpuestas. ${ }^{31}$ Primero fue Francisco de Montejo el mozo, a quien su padre nombró en 1535 teniente de gobernador de la provincia. Desde 1537, fecha de la marcha del hijo del adelantado a la conquista de Yucatán, y hasta 1548, los tenientes de gobernadores y alcaldes ordinarios que se sucedieron en la provincia y en la villa de Santa María de la Victoria, fueron nominados directamente por el adelantado (Juan Ortiz de Gatica, Alonso López, Gonzalo Nieto, Diego de Córdoba). Era, pues, evidente la intención del adelantado Montejo por mantener un control incuestionado sobre la provincia. ${ }^{32}$

Se le imputaba a Montejo, en su juicio de residencia, de posible fraude al conceder cédulas de encomiendas a parientes y amigos, después de recibir provisiones reales en las que se le mandaba que no encomendase indio alguno a sus familiares más directos. Hubo testigos, como el encomendero y vecino Diego Alver de Soria, que afirmaban que el adelantado hizo repartimientos de pueblos de indios que estaban puestos en familiares

29 García Bernal: Población y encomienda..., pág. 191.

30 AGI, Guatemala, 965, Memorial de lo que en nombre de S.M. se ha de alegar contra lo que pide el adelantado Maldonado.

31 AGI, Justicia, 300, n. ${ }^{\circ}$ 2, r. 3, Relación de la residencia de Francisco de Montejo, gobernador de Yucatán, por Blas Cota, 1548-1553, fols. 618-727; López de Cogolludo, Fray Diego: Los tres siglos de la dominación española en Yucatán, o sea Historia de esta provincia, Graz, 1971, vol. I, págs. 364-365.

32 Chamberlain: The Governorship..., págs. 190-197; AGI, Justicia, 300, n. o 2, r. 3, Relación de la residencia de Francisco de Montejo... 
suyos de forma poco clara, en personas de su entorno, como su sobrino Francisco de Montejo, Diego de Córdoba, Juan de Lepe y Rodrigo Alvarez. ${ }^{33} \mathrm{El}$ adelantado se defendió aduciendo que en el momento que llegaron las citadas provisiones reales de la Audiencia de los Confines, ni él ni sus familiares más directos tenían repartimiento de indios en Tabasco y que dichos pueblos encomendados eran de Alonso López, ya difunto, y que él los puso en dichas personas arriba señaladas. Sólo los pueblos de Xicalango y Atasta, "que el uno tiene 19 casas y el otro 14... luego que se me notificó la dicha provisión de S.M. los dejé en cabeza de S.M". ${ }^{34}$

Los efectos de las provisiones que llegaron desde la Audiencia de los Confines dirigidas al adelantado Montejo y su entorno familiar fueron claros y contundentes:

"En Tabasco quitó un repartimiento a un Francisco de Montejo hijo natural del Adelantado así por ser su hijo como porque tenía otro repartimiento en Yucatán muy grueso. Quitó en Tabasco otro repartimiento a Francisco de Montejo sobrino del Adelantado por tener dos repartimientos en diferente provincias, quedóle un repartimiento rico en Yucatán. Quitó asimismo otros indios en Tabasco como fue al mismo Adelantado y a su mujer Doña Beatriz y una nieta..... ${ }^{35}$

Francisco de Montejo el sobrino poseía varias encomiendas en Tabasco y en Yucatán. En un principio no fueron removidas por las autoridades de la Audiencia de los Confines; sin embargo, las que tenía en Tabasco, Ocelotlan, Tacotalpa y la mitad de Tecomaxiaca, fueron puestas en la Corona pues no se podía tener encomiendas de indios en dos provincias distintas. ${ }^{36}$ Muerto Montejo el sobrino, las seis encomiendas que disfrutaba en Yucatán pasaron a manos de su mujer Beatriz de Montejo, quien se casó en segundas nupcias con don Diego de Santillán. ${ }^{37}$

En cuanto al destino de las encomiendas separadas al adelantado Montejo y sus familiares hubo diferentes planteamientos. Por una parte estaban algunos vecinos, antiguos conquistadores y pobladores pobres, que

33 AGI, Justicia, 300, n. ${ }^{\circ}$ 2, r. 3, Relación de la residencia de Francisco de Montejo...

34 Ibídem.

35 AGI, Guatemala, 9A, doc. 29, Relación de lo que V. Ilma. ha mandado se le dé por memoria de las cosas tocantes a las provincias de Yucatán, Campeche, Cozumel y Tabasco, s/f.

36 AGI, Guatemala, 386, L. I, Cédula real dirigida al presidente y oidores de la Audiencia de loa Confines sobre ciertos pueblos de indios que tiene Francisco de Montejo y otros, Madrid, 9 de junio de 1553. fols 93v.-94r; Recopilación de las Leyes de Indias, libro VI, título IX, ley 24.

37 AGI, Patronato, 80, n. ${ }^{\circ}$, r. 5, Probanza de méritos y servicios del capitán Francisco de Montejo, sobrino del Adelantado don Francisco de Montejo, con quien anduvo en la conquista y pacificación de la provincia de Yucatán y después en allanar y repartir aquella tierra, Mérida, 22 de abril de 1591. 
veían en dicha remoción una posible salida a las necesidades y penurias que estaban soportando en un territorio nada apropiado para lograr un enriquecimiento rápido, como era la provincia de Tabasco:

“... pretendían que pues el dicho adelantado ni su mujer e hijos e hijas no podían tener ninguno indios y los más de los vecinos de esta dicha villa estaban pobres, repartiesen entre ellos los dichos pueblos para con que se pudiesen sustentar los que habían conquistado y poblado la tierra....". ${ }^{38}$

En otro sentido estaban quienes consideraban que las encomiendas expropiadas a los Montejo debían estar puestas en cabeza de la Corona. Este planteamiento era apoyado por los franciscanos de la provincia de Yucatán, donde se concentraba la mayor parte de las encomiendas del adelantado Montejo y su familia. ${ }^{39}$ Alegaban los frailes que la incorporación de estas encomiendas a la Real Corona favorecía la conservación de los indígenas:

“... tenemos los religiosos por experiencia en México y en Guatemala y acá en Yucatán, que se planta mejor la doctrina y predicación evangélica y hay mejor cristiandad en los pueblos realengos que no en los de encomenderos por tener menos tributos y estar libre de servicio personal y tener más libertad de acudir a los sermones y monasterios donde se doctrinan y bautizan...." ${ }^{40}$

Las posibilidades de salidas para aquellos conquistadores y pobladores pobres, que no habían podido acceder al sistema de encomiendas, se encontraban en recibir de las autoridades rentas en concepto de ayudas de costa, procedentes de los tributos sacados de las encomiendas incorporadas a la Real Corona, la mayor parte de ellas de los Montejo. Las miras de los franciscanos estaban puestas mucho más lejos. Pedían al rey que todas las encomiendas que quedaran vacantes fueran incorporadas a la Corona, pues era lo más beneficioso para los indios. Sin embargo, tampoco buscaban dejar desamparados a muchos antiguos conquistadores y pobladores que todavía optaban a la única compensación que la provincia ofrecía, la encomienda:

38 Ibídem.

39 González Cícero: Perspectiva religiosa..., pág. 138.

40 Carta de fray Luis de Villalpando, fray Diego de Béjar y fray Miguel de Vera a S.M., dando relación de cosas tocantes al bien de los naturales y españoles de las provincia de Yucatán, Campeche, 29 de julio 1550, en: Scholes, France V., Carlos Menéndez, J. I. Rubio Mañé y Eleanor Adams: Documentos para la Historia de Yucatán, Mérida, Yuc., México, 1936, vol. 1, págs. 3-5. 
“... por recibir por nuestra causa provecho los indios no reciban daño los encomenderos,... como vuestros servidores, reciban de vuestra real caja el salario o merced que de los tributos de los mismos indios Vuestra Alteza les señalare para que los puedan llevar con buena conciencia". ${ }^{41}$

Los franciscanos criticaron las acciones de las autoridades virreinales, que volvieron a encomendar pueblos que habían sido puestos en la Corona Real. La lejanía de estas tierras de los centros de poder político, así como la ausencia de autoridades que mirasen por los intereses de la Hacienda real y de los indígenas, hacían posible estas situaciones, que los franciscanos de la provincia de Yucatán consideraban irregulares:

“... y otros que el licenciado Herrera juez de residencia repartió aquí estando vacuos sin tener para ello autoridad; y otros de aquí y de Tabasco que habiéndolos puesto en Vuestra Real Corona año y medio había Cerrato presidente de la Audiencia de los Confines, los quitó de ella el dicho licenciado Herrera que es ahora Oidor en México y los repartió en encomenderos de Yucatán y de Tabasco; y aún hasta los dineros que habían rentado en este dicho tiempo algunos de ellos los sacó de Vuestra Real Caja y los repartió también en encomenderos....". ${ }^{42}$

En Tabasco, buena parte de los pueblos encomendados en los Montejo, que, como se ha señalado, estaban en manos de personas interpuestas, una vez que fueron removidos no pasaron a la Corona, sino a manos de otros encomenderos. Así, los pueblos de Tecoluta, Omitán, Xalpa, Soyataco, Huaimango, Tamulte y Nacaxoxuca — que, según consta en la residencia que se le tomó al adelantado Montejo, pertenecieron a miembros de su familia en primer grado, aunque formalmente estaban bajo los nombres de otras personas, cuando supieron que el adelantado, su mujer e hijos no podían tener los dichos pueblos- ${ }^{43}$ no pasaron a la Corona Real como otros (Tapixulapa, Astata, Xicalango), sino que fueron encomendados en personas particulares.

Después de la destitución de Montejo y hasta 1562, cuando la Corona concede al alcalde mayor de Yucatán, Diego Quijada, la facultad de encomendar indios, ${ }^{44}$ ésta sólo pudieron realizarla los visitadores que desde la Audiencia de los Confines se enviaron a los antiguos territorios admi-

41 Ibídem.

42 Ibídem.

43 AGI, Justicia, 300, n. ${ }^{\circ}$ 2, r. 3, Relación de la residencia de Francisco de Montejo...

44 Real cédula al alcalde mayor de Yucatán, Dr. Diego Quijada, para poder encomendar indios, Madrid, 12 de enero de 1562, en: Scholes, France V. y Eleanor B. Adams: Don Diego Quijada, Alcalde Mayor de Yucatán, 1561-1565, México, 1938, vol. I, pág. 17. 
nistrados por el adelantado: Tomás López Medel, en 1552, y García Jofre de Loaiza, en $1560 . .^{45}$

Conforme los territorios indianos fueron adquiriendo importancia y la complejidad de la administración hispana se fue extendiendo, la atención e intervención de la Corona en los asuntos de Indias aumentaban gradualmente. Durante todo el transcurso de la dominación española fue pauta organizar el gobierno de los dominios americanos de tal suerte que rindieran el mayor beneficio posible a la Hacienda real.

En provincias y áreas marginales como Yucatán, Tabasco y Chiapas los únicos beneficios que, en cierta manera, podían compensar a particulares, en principio, y a la Real Corona, a posteriori, eran los ingresos provenientes de los tributos indígenas. La ausencia de minas de oro y plata en estos territorios hizo que una institución como la encomienda fuera la única fuente de compensación que asegurase la presencia y permanencia de los españoles.

Atender la fuerte demanda de repartimientos entre los conquistadores, ahora pobladores, que habían participado en el largo proceso conquistador, fue una de las prioridades que tomaron las diferentes autoridades de estas provincias hasta la implantación de las Leyes Nuevas. En esos primeros momentos de presencia española resulta tremendamente difícil que se pudiese encomendar indios en la Real Corona.

La primera visita de los pueblos de la provincia de Tabasco realizada en 1541 por Alonso López nos muestra que todos los repartimientos estaban puestos en los vecinos que poblaban la villa de la Victoria. Era normal que, en esos momentos, ante la falta de oportunidades para un enriquecimiento fácil y rápido, las encomiendas fuesen reservadas esencialmente a particulares y no a la Real Corona.

Se tendrá que acudir a la tasación efectuada por el licenciado Cerrato en 1549 para advertir la presencia de encomiendas en poder de la Real Corona. De los nueve pueblos tasados cuatro estaban en la Hacienda real, concretamente los más importantes de la provincia. Precisamente eran estos pueblos los mismos que se removieron al adelantado Montejo y a sus familiares (Tabasco, Tapixulapa, Tamulte y Xicalango). ${ }^{46}$ Los pueblos de Tacotalpa, Ocelotlan y la mitad de Tecomaxiaca, siguieron tributando, aunque por poco tiempo, a su sobrino y homónimo, Francisco de Montejo.

45 Zavala: La encomienda..., págs. 617-624

46 AGI, Guatemala, 128, Tasaciones de la villa de la Victoria de la provincia de Tabasco que es junto a Yucatán, 1549, fols. 397-401; Paso y Troncoso: Epistolario..., vol. VI, págs. 107-112. 
Debemos tener en cuenta que, a pesar de estar estos pueblos en cabeza del rey, sus ingresos no fueron a parar a las arcas reales. La Corona había dispuesto que los tributos procedentes de las encomiendas expropiadas a los Montejo se distribuyeran como ayudas de costa entre los conquistadores y sus descendientes que no poseían encomiendas. ${ }^{47}$

En las "Cuentas de la Real Hacienda" correspondientes al período 15611577 observamos una ligera variación en los pueblos de realengo. Tamulte y Tabasco dejaron de tributar a la Hacienda real y fueron puestos en cabeza de particulares..$^{48}$ Por otra parte, los pueblos de Ocelotlan y Tacotalpa, que pertenecieron a Francisco de Montejo el sobrino, junto con Xicalango y sus sujetos (Atasta y Jonuta), Tapixulapa y el pequeño pueblo de Tamamulco, formaron los pueblos que pertenecían a la Real Corona. ${ }^{49}$ Esta lista se ve asimismo confirmada en la "Relación de la Provincia de Tabasco de 1579", donde se menciona que Xicalango, en estos años, se despobló pasando sus escasos habitantes al cercano pueblo de Jonuta, y ya Tamamulco no aparece recogido. ${ }^{50}$

La importancia de estos pueblos de la Real Corona queda manifiesta si tenemos en cuenta algunos datos estadísticos. Para 1579, de los 61 pueblos que aparecen en la "Relación de la Provincia de Tabasco", seis, es decir, 9'8 \% del total, estaban en manos de la Real Corona, y de los 2.396 tributarios de la provincia, los pueblos realengos comprendían 477, 19'9 \% de los mismos. Ocelotlan y Tapixulapa, con 240 y 110 tributarios respectivamente, eran el segundo y cuarto pueblos con más tributarios de la provincia y Tacotalpa y Xicalango, éste junto con sus sujetos, no bajaban de 60, teniendo en cuenta que la media de tributarios era de $39 .{ }^{51}$ Esto es una evidencia de que el adelantado Montejo y su familia llegaron a poseer los mejores repartimientos de indios de la provincia.

A lo largo de todo este período, los pueblos realengos aumentaban cuando se incorporaban a la Corona aquellas encomiendas que por muerte de sus poseedores permanecían vacantes. Estas anexiones eran provisionales en el tiempo, en tanto se tramitaba su nueva concesión. Las provisiones entregadas al oidor Tomás López en 1552 señalaban que todas las enco-

47 García Bernal, Población y encomienda..., págs. 202-203.

48 El antiguo pueblo prehispánico de Potonchán aparece en unas fuentes como Tabasco y en otras como Tabasquillo.

49 AGI, Contaduría, 911, r. 1, 2, 8 y 12, Cuentas de la administración de la Real Hacienda de los años 1560-1577.

50 Relaciones Histórico-Geográficas de la gobernación de Yucatán, "Relación de la Provincia de Tabasco", México, 1983, vol. II, págs. 373-378.

51 Ibídem. 
miendas que quedasen vacantes en las provincias de Yucatán, Tabasco y Cozumel, fuesen encomendadas en aquellas personas que las merecieran, teniendo preferencia aquellos conquistadores que hubieren participado en la conquista y pacificación de las mismas y que no tuviesen indios de repartimiento. Según las mismas ordenanzas, sólo debían permanecer bajo la jurisdicción de la Real Corona los pueblos de indios que se quitaron al adelantado Montejo y su familia. ${ }^{52}$ Ya destacamos anteriormente la oposición de los padres franciscanos de la provincia de San José de Yucatán a que los pueblos encomendados en el rey pasasen de nuevo a particulares. ${ }^{53}$

Pueblos como Tecomaxiaca, Chilapa, Guatacalco y Xalapa, que fueron vacando por la muerte de sus encomenderos, se incorporaron a la Real Corona y a ella tributaron provisionalmente sus indios hasta que no se concedieron de nuevo a particulares:

"Tasación del pueblo de Guatacalco... parece estar tasado en 25 xiquipiles de cacao y 24 gallinas, la mitad de la tierra y la mitad de Castilla y 12 brazas de red y 4 cestos y 2 petates, 2 sementeras de maíz de 150 mazorcas cada sementera, hacésele cargo al dicho oficial... de la mitad de los dichos tributos por el tiempo que estuvieran vacos los dichos tributos antes que se encomendasen en el dicho García de Ledesma....".54

La política de concentración de encomiendas en la Corona encontró oposición entre los vecinos, conquistadores y pobladores. En 1561 el Cabildo de la ciudad de Mérida ya se dirigió al rey pidiendo que se le diera a la máxima autoridad de la Alcaldía Mayor la facultad de "encomendar y repartir los indios y repartimientos que vacaren en estas provincias y Tabasco en conquistadores y personas que tengan méritos...". ${ }^{55}$ Con anterioridad, una vez que pasaron a la autoridad real los territorios que conformaron la antigua gobernación del adelantado Montejo, las primeras facultades para encomendar indios se dieron a los visitadores Tomás López y García Jofre de Loaiza en 1552 y 1561, respectivamente. En 1562, la Corona volvió a dar dicha autorización. En este caso, al alcalde mayor de Yucatán, Diego de Quijada:

52 Provisión real a Tomás López para poder encomendar los naturales de Yucatán, Cozumel y Tabasco, 9 de enero de 1552, en Rubio Mañe, J. Ignacio: Archivo de la Historia, vol. I, págs. 133-138; Zavala: La encomienda..., pág. 617.

53 Carta de fray Luis de Villalpando, fray Diego de Béjar y fray Miguel de Vera a S.M., Campeche, 29 de julio 1550, en Scholes y otros: Documentos..., vol. 7, págs 3-5.

54 AGI, Contaduría, 911, n. ${ }^{\circ}$ 1, Cuentas de la administración de la Real Hacienda de los años $1560-1577$

55 Carta del Cabildo de la ciudad de Mérida a S.M., Mérida, 6 de octubre de 1561, en: Scholes y Adams: Don Diego Quijada..., vol. I, págs. 13-15. 
“...para que por el tiempo que nuestra merced y voluntad fuere, los indios que vacaren en esas provincias, teniendo vos el dicho cargo, los podáis encomendar y encomendáis a los españoles que en ellas residen y residieren...". ${ }^{56}$

Quijada fue acusado de encomendar indios vacantes en personas que no eran conquistadores ni antiguos pobladores, como más adelante se verá. Es más, se le achacó que dichas encomiendas pasaron a manos de criados y allegados del citado alcalde mayor de Yucatán, "y lo mismo ha proveído de ayudas de costas, oficios y otros aprovechamientos". ${ }^{57}$

Diego de Quijada llegó a utilizar los rendimientos de las encomiendas vacantes para atender las necesidades de pueblos y rancherías en los pueblos cimatanes que, en esos años, fueron sujetados:

“... y para doctrinar e industriar a las cosas de la Santa Fe Católica les ha poblado y hecho sus casas entre los pueblos de Cuaquilteupa y Cunduacan en el asiento nombrado Santiago de Cimatán y para este efecto les mandó hacer allí sus casas y les proveyó de bastimentos y les ha mandado hacer sementeras porque no padezcan necesidad y no se ausente ni vengan a disminución...". ${ }^{58}$

Precisamente, uno de los cargos que se presentaron contra Quijada, durante su juicio de residencia en Tabasco, estaba centrado en el mal uso que se dio a lo que montaron y valieron dichas vacantes - las encomiendas que vacaron por la muerte de los encomenderos Pedro de Oribe, Alonso de la Tovilla, Juan de Solís y Diego Vázquez Ribadeneyra-. Concretamente, fue acusado de haberse apoderado del valor de las vacantes y de no ponerlas en la Real Corona como debía y estaba obligado, con objeto de disponer fondos en las Cajas Reales para pagar los salarios de las diversas autoridades provinciales y eclesiásticas:

“... lo que se remataba, ni cuenta ni razón como estaba obligado, ni almoneda ni remate se sacó ni se vio cosa alguna de las dichas menudencias... aunque dice que gastó parte de ello en una ranchería se hizo en unos indios que estaban en unos montes de Cimatán..... ${ }^{59}$

56 Real cédula al Dr. Diego de Quijada para poder encomendar indios, Madrid, 12 de enero de 1562, ibídem, pág. 17.

57 AGI, Guatemala, 9A, n. ${ }^{\circ}$ 29, r. 125, Relación de lo que V. S. ${ }^{\text {a }}$ Ilma. ha mandado se le dé por memoria de las cosas tocantes a las provincias de Yucatán, Campeche, Cozumel, Tabasco, s/f (h. 1565).

58 AGI, Justicia, 249, Residencia al Alcalde Mayor de la provincia de Yucatán, Dr. D. Diego de Quijada. Testimonio de lo que de la vacante se gastó en poblar los Cimatanes, Sta. María de la Victoria, 19 de julio de 1564 .

59 Cargos de residencia contra el doctor Diego de Quijada que resultaron de la pesquisa hecha en Tabasco, Mérida, 16 de febrero de 1566, en: Scholes y Adams: Don Diego Quijada..., vol. II, págs. 350-355. 
Por su parte, el doctor Diego de Quijada aducía que todo lo que rentaron dichas encomiendas el tiempo que permanecieron vacantes estuvo en nombre de su depositario en Tabasco Diego Alver de Soria, dedicándose dichas rentas, en su totalidad, a "vestir y remediar los indios de los pueblos de Cimatán, Naopa y Acatán, que Gómez de Sotomayor, teniente, y yo trajimos de paz y pusimos debajo del real dominio, los cuales poblé entre los pueblos de Cunduacán y Cualquiteupa y les mandé hacer casa e iglesia y los puse en cabeza de S.M....". ${ }^{60}$

Estos repartimientos, que poseyeron hasta sus respectivos óbitos Diego Vázquez Rivadeneira, Juan de Solís, Alonso de la Tovilla y Pedro de Uribe, fueron depositados de nuevo en personas particulares y no en la Real Corona y, concretamente, en personas cercanas al doctor Diego de Quijada. En su juicio de residencia, se elevaron cargos contra él por estos hechos que se consideraron anómalos. ${ }^{61}$

Las encomiendas de Juan de Solís - Ayapa, Mecaguacan, Gueytalpa, Teotitáncopilco - fueron puestas en manos de Juan de Villafranca. Según los cargos, Juan de Solís poseía dichos repartimientos sin títulos algunos pues pertenecían a su primera esposa, ya fallecida, y Diego de Quijada los puso en la Real Corona tras la muerte de aquél, encomendándolos posteriormente en Juan de Villafranca al casarse con la segunda mujer del citado Solís, "y los dejó de dar y encomendar en personas beneméritas como S.M. lo tiene mandado". ${ }^{62}$ Quijada se defendió de este cargo aduciendo que nunca pasaron estos pueblos vacantes a la Real Corona:

"Sólo di un mandamiento, estando en esta ciudad, dirigido a Antonio de Tolosa, oficial de la Hacienda Real de aquella provincia, por el cual mandé que entretanto que no se encomendase, recogiese los tributos y los metiese en la Real Caja...”. ${ }^{63}$

Para Quijada, el mérito por el cual se encomendaban en Juan de Villafranca los pueblos que pertenecieron al difunto Juan de Solís no estaba en haberse casado con la segunda mujer de éste, Elvira Ponce, sino que el sim-

60 Respuesta del doctor Quijada a los cargos de residencia para Tabasco, Mérida, 19 de febrero de 1566, ibídem, págs. 356-362.

61 Cargos de residencia contra el alcalde mayor de la provincia de Yucatán, Diego de Quijada, Mérida, 31 de enero de 1566, ibídem, vol. II, págs. 232-260; Descargos de Diego de Quijada, Mérida, 12 de febrero de 1566, ibídem, págs.260-308.

62 Cargos de residencia contra el alcalde mayor de la provincia de Yucatán, Diego de Quijada, Mérida, 31 de enero de 1566, ibídem, págs. 232-259.

63 Descargos de Diego de Quijada, Mérida, 12 de febrero de 1566, ibídem, págs. 269-308. 
ple hecho de casarse con la hija de uno de los primeros conquistadores de México era buen mérito para podérsele hacer dichas encomiendas. ${ }^{64}$

Las encomiendas que quedaron vacantes por la muerte de Pedro de Uribe -Amatitán y Cunduacán-, fueron puestas en manos de su esposa Ana de Sornoza. El doctor Quijada depositó estos tributos en su teniente de gobernación de Tabasco, Gómez de Santoyo, a la espera de que la Real Audiencia de la Nueva España hiciera provisión de dichos repartimientos en Ana de Sornoza, como así finalmente sucedió. A pesar de ello, Gabriel Hernández, criado del doctor Quijada, casó con la citada encomendera. ${ }^{65}$

Por otra parte, los repartimientos que pertenecieron a Alonso de la Tovilla $-1 / 2$ de Xalupa y Boquiapa-, fueron encomendados en Pedro Interian, "porque es muy honrado vecino y antiguo en la dicha villa". ${ }^{66}$ En el cargo que se le hace a Quijada sobre este asunto, se le recrimina el haber casado a su sobrina, María Quijada, con don Gregorio de Cetina, al que le había dado en propiedad las encomiendas que vacaron por muerte de Francisco de Cepeda en Campeche, y no dárselas a la viuda de éste, que se casó con el citado Pedro Interian en la villa de Santa María de la Victoria. ${ }^{67}$ Diego de Quijada adujo en su descargo que las encomiendas de Cepeda en Campeche habían quedado vacantes al haber pasado las dos vidas "de que S.M. tiene hecha merced a los encomenderos de estas partes" ${ }^{68}$ Por lo tanto, podía encomendarlas de nuevo y así lo hizo, poniéndolas en Gregorio de Cetina. Las encomiendas de Alonso de la Tovilla, la mitad de Xalupa y Boquiapa, que quedaron vacantes por su muerte, pasaron a Pedro Interian, "y porque la mujer del dicho Francisco de Cepeda no quedase perdida y se remediase se los di con condición que casase con ella, y en esto se hizo buen servicio a Dios y a S.M., que es el que yo siempre he pretendido y no otro algún interés humano". ${ }^{69}$

Como en los anteriores casos, Quijada señala que nunca estos repartimientos, que quedaron vacantes por la muerte de su dueño, estuvieron en

64 Ibídem

65 Cargos de residencia contra el alcalde mayor de la provincia de Yucatán, Diego de Quijada, Mérida, 31 de enero de 1566, ibídem, págs. 232-259; Descargos de Diego de Quijada, Mérida, 12 de febrero de 1566, ibídem, págs. 269-308.

66 Respuestas del doctor Quijada a los cargos de residencia para Tabasco, Mérida, 19 de febrero de 1566, ibídem, págs. 356-362.

67 Cargos de residencia contra el doctor Quijada que resultaron de la pesquisa hecha en Tabasco, Mérida, 16 de febrero de 1566, ibídem, págs. 350-355.

68 Respuestas del doctor Quijada a los cargos de residencia para Tabasco, Mérida 19 de febrero de 1566, ibídem, págs. 356-362.

69 Ibídem. 
cabeza del rey, sino que por mandamiento suyo el tesorero de la provincia de Tabasco cobró los tributos que rentaron hasta que tuviesen un nuevo encomendero, en este caso Pedro Interian. ${ }^{70}$

Por último, las encomiendas de Diego Vázquez Rivadeneyra - 1/2 de Tamulte de la Barranca y Oxiacaque - fueron puestas en García de Avendaño, amigo de Quijada y criado que fue del obispo de Chiapas. Según los cargos, el alcalde mayor de Yucatán obligó a la viuda de Vázquez Rivadeneyra a casarse con Avendaño, a lo que ésta en principio se negó alegando que dichas encomiendas le pertenecían a ella, según cédula del rey. ${ }^{71}$ Estas encomiendas, mitad de Tamulte de la Barranca y Oxiacaque, las encontramos en 1579 puestas en Diego Alver de Soria, vecino y antiguo tesorero de la Real Hacienda de la provincia de Tabasco, y que unos años antes se dirigió al rey para que tuviera en consideración sus servicios y antigüedad en aquella tierra y se le encomendase algún repartimiento vacante o el primero que vacare. ${ }^{72}$

Muchos vecinos, como fue el caso citado de Diego Alver de Soria, optaban por enviar al Consejo de Indias y al rey memoriales y probanzas de méritos y servicios. Gracias a ellos expresaban a las autoridades la necesidad de que se les diese o encomendase algún repartimiento de indios que estuvieren o quedasen vacantes. Como ya se ha referido, dada la carencia de otras granjerías en estas provincias, seguía siendo la encomienda el único medio de mantenimiento de la república de españoles, a pesar de los sucesivos intentos de los oficiales reales por ir incorporando progresivamente las encomiendas vacantes en la Corona Real.

En 1591, el alcalde mayor de la provincia de Tabasco, Juan Ruiz de Aguirre, en una carta dirigida al rey, dio cuenta de que las encomiendas rentaban pocos aprovechamientos. Estimaba que, para que la provincia se poblase, convendría que el rey diera facultad a los alcaldes mayores de Tabasco para poder encomendar los indios que fuesen vacando:

“... con esto la tierra se poblará y aumentará, que es lástima ver cuán despoblada está la villa que no hay en ella cuatro o seis vecinos y toda gente pobre causado esto tam-

70 Ibídem.

71 Cargos de residencia contra el doctor Quijada que resultaron de la pesquisa hecha en Tabasco, Mérida, 16 de febrero de 1566, ibídem, págs. 350-355; Recopilación de la leyes de Indias, libro VI, título XI, ley I.

72 "Relación de la Provincia de Tabasco", en Relaciones Histórico-Geográficas, vol. II, págs. 373-378; AGI, México, 99, doc. 1, Diego Alver de Soria, vecino de Santa María de la Victoria de la provincia de Tabasco, s/f. 
bién haber habido una retasa en los tributos que hizo el Audiencia Real y los dejó pobrísimos.... ${ }^{73}$

Iniciado el siglo XVII, el descenso de la población española se hacía notar. La pobreza de la región en toda su extensión — dificultades creadas por las especiales condiciones geográficas de la provincia; enormes distancias existentes con los centros de decisión política; descenso de la población indígena y, por lo tanto, disminución de los tributos; poco o escaso atractivo económico de la provincia (centrado únicamente en las rentas procedentes de las encomiendas y en un comercio regional muy marginal y poco aprovechado); la cada vez mayor presión de corsarios y piratas-, explica el progresivo alejamiento de la escasa población española, buscando mayor seguridad en otras áreas del virreinato.

Todo ello implicaba que muchos encomenderos, debido a que sus rendimientos eran escasos y poco atractivos, hicieran dejación de sus repartimientos. Esto, junto a los que iban quedando vacantes por muerte de sus poseedores, estimuló que se fueran concentrando encomiendas, especialmente las de menos valor, en los pocos encomenderos presentes en la provincia.

Así, Alonso de Rebolledo, hijo de Juan de Rebolledo - antiguo contador de la Real Hacienda de la provincia de Tabasco y alcalde ordinario que fue de la villa de Santa María de la Victoria-, y nieto de Alonso de Elvira el viejo - uno de los principales y antiguos conquistadores de la provincia-, recibió en encomienda la mitad de los pueblos de Tamulte de la Barranca, Tamulte de la Sabana, Oxiacaque, Huaymango, Apazta, Oceloteupa y Ulapa, que pertenecieron a Fernando Parias Zapata, "que por habérsele dado y encomendado en esta dicha provincia (Yucatán) otra encomienda quedó como es dicho vaca y se puso edicto de ella conforme a lo que el rey nuestro señor tiene proveído y ordenado en semejantes vacaciones..." ${ }^{74}$ Las otras mitades de los pueblos ya citados y antiguamente encomendados en Fernando Parias Zapata, se pusieron en Francisco Ortiz, hasta entonces vecino de la villa y puerto de Campeche. ${ }^{75}$ Este también recibió los repartimientos de Cuilzapotan y Macuspana, pertenecientes a Alonso de Rebolledo, "que por la nueva merced que se le hizo arriba declarado que-

73 AGI, México, 112, doc. 3, El alcalde mayor de la provincia de Tabasco a S.M., Acayapa de Tabasco, 6 de mayo de 1591 .

74 AGI, México, 125, doc. 1, Autos de la concesión de ayudas de costa a Juan Bautista Rejón Arias, Mérida, 31 de marzo de 1605.

75 Ibídem. 
daron vacos" ${ }^{76}$ así como de los pueblos de Culico, Soyataco y Chichicapa, que poseía Alonso Pacheco de Sopuerta "que por no haber ido a residir y hacer vecindad en la dicha villa de Tabasco conforme a lo ordenado y mandado por S.M. declaré por vacos". ${ }^{77}$

Otro encomendero que logró agrupar un buen número de encomiendas fue Cristóbal Tello de Aguilar. Por muerte de Margarita de Paz, los pueblos de Coquiteupa, Puxcatan, y la mitad de los de Tamulte de la Barranca y Tamulte de la Sabana, fueron depositados en enero de 1605 en el citado Tello de Aguilar. ${ }^{78}$ Cumpliendo con lo que se especificaba en cédulas y provisiones, dicho encomendero, al igual que el resto, debía de vivir y estar poblado en la villa de Santa María de la Victoria, sin salir de ella sin expresa licencia. ${ }^{79}$ La Corona, a través de provisiones enviadas a las autoridades provinciales y locales, señalaba la importancia y el deber de que los encomenderos residieran y asistieran en la Victoria:

“... la voluntad de S.M. es que la villa de Santa María de la Victoria esté poblada para que estándolo se excusen de robos y daños que el inglés y otros enemigos hacen hoy y cada día... y que para su reparo tiene mandado que las personas en quien se encomiendan pueblos de indios de la provincia estén y asistan en esa dicha villa con sus casas pobladas haciendo vecindad y acudiendo a la defensa de ella con sus personas, armas y caballos en las ocasiones que se ofrecieren sin hacer ausencia a parte alguna..." ${ }^{80}$

Eran, pues, evidentes los deseos de la Corona y las autoridades por evitar el despoblamiento general de la única villa de españoles existente en un área marginal como la provincia de Tabasco. En el caso de Cristóbal Tello de Aguilar, pese a dichas advertencias, se puede observar que el gobernador de Yucatán, Carlos de Luna y Arellano, tuvo que hacer suspensión por ausencia de sus encomiendas nueve meses después de habérselas concedido:

“... habiendo visto que... Cristóbal Tello de Aguilar encomendero... contraviniendo a las cédulas de S.M. en que precisamente manda que los encomenderos de aquella pro-

76 Ibídem. Estos pueblos estaban encomendados en 1579 en su padre, Juan de Rebolledo, en segunda vida, "Relación de la Provincia de Tabasco", en: Relaciones Histórico-Geográficas, vol. II, págs. 373-378.

77 AGI, México, 125, doc. 1, Autos de la concesión de ayudas de costa a Juan Bautista Rejón Arias, Mérida, 31 de marzo de 1605

78 AGI, México, 126, Autos y mandamientos sobre la vacante de las encomiendas de Cristóbal Tello de Aguilar de la provincia de Tabasco, Mérida, 25 de abril de 1607.

79 Recopilación de la leyes de Indias, libro VI, título IX, ley X.

80 Ibídem. 
vincia asistan y hagan vecindad en la villa de la Victoria... lo cual el dicho Cristóbal Tello de Aguilar no cumplió, antes se vino a estas provincias (Yucatán) sin licencia alguna dejando despoblada por su parte la dicha villa, lo cual mandóse pongan edictos de vacante de las dichas encomiendas para proveerlas en conformidad de la facultad". ${ }^{81}$

Cumplido el primer cuarto del siglo XVII, las rentas que producían las encomiendas tabasqueñas seguían siendo muy bajas. Como señala un documento de la época:

“... hay pueblos entre ellos tan pequeños que muchos tienen a 8 y 10 tributarios y los mayores no pasan de 40 ó $50 \ldots$ con lo cual se verifica la deterioración en que están aquellos pueblos y no tener congrua el encomendero por ser muy cara la dicha provincia y entrar de acarreo los bastimentos en ella y tener obligación a sustentar armas y caballo por lo cual cuando vacaba la renta de las dichas encomiendas no había quien se quisiese oponer a ellas....". ${ }^{82}$

La solución parecía que estribaba en la acumulación de repartimientos para que las rentas pudiesen sustentar a los escasos encomenderos que iban quedando en la provincia:

“... y así fue necesario para que no viniera en total ruina el beneficio de los dichos pueblos, esperar a que por muerte de algunos encomenderos agregando a un cuerpo lo que rentaba hubiese renta...." ${ }^{83}$

Simón Nieto de Salazar, descendiente de conquistadores y pobladores que ejercieron cargos políticos y de responsabilidad de la provincia de Tabasco desde la etapa del adelantado Francisco de Montejo, fue uno de los encomenderos que acumuló un buen número de pueblos indios que quedaron vacantes en la provincia:

"Tecomaxiaca, Mazateupa, Usumacinta, Tamulte de Popane (Popane), Istapilla, Jalupa, que vacaron por fin y muerte de don Alonso de Texeda y Mateo de Urriaga, y el pueblo de Tabasquillo de que hizo dejación Juan Tomelín y la mitad de los pueblos de Tamulte de la Barranca, Tamulte de la Sabana, Oxiacaque, Huaymango, Apasta, Oceloteupa, Julapa, de que asimismo hizo dejación Alonso de Rebolledo, encomenderos que fueron de los dichos pueblos que están en la provincia de Tabasco que rentan cada año 400 ducados...". ${ }^{84}$

81 Ibídem.

82 AGI, México, 143, n. ${ }^{\circ}$ 2, doc. 27, Título de encomienda de Simón Nieto de Salazar, Mérida, 28 de junio de 1625 .

83 Ibídem.

84 Ibídem. 
Como compensación paralela a las encomiendas se encontraba la fórmula de las llamadas "ayudas de costa". La Corona, amparándose en la expropiación de las encomiendas de los Montejo, quiso que los beneficios procedentes de los tributos que dichos repartimientos producían fuesen a parar a manos de aquellos buenos pobladores que no hubiesen obtenido encomiendas.

Sin embargo, también se generalizó el abuso en este sistema de prestaciones. Muchas de las ayudas de costa fueron a parar a personas que ya gozaban encomiendas o que residían fuera de la jurisdicción provincial y no necesitaban tales ayudas. El alcalde mayor de Yucatán, Diego Quijada, expuso al rey algunos abusos que se producían al respecto en la provincia de Tabasco. Según relata Quijada, Francisco de Morales, relator de la Audiencia de Nueva España, recibía de la Caja Real de Tabasco 300 pesos de tipuzque procedentes de las ayudas de costa de la provincia. Precisaba que esto suponía un agravio para los que residían en Tabasco y mantenían aquella tierra, teniendo en cuenta que el citado Morales no había vivido ni tenido contacto alguno en Tabasco:

"En efecto, se le han pagado y pagan al dicho Francisco de Morales. En todas estas provincias no hay otra ayuda de costa ni se da al día de hoy a persona alguna, aunque cierto hay algunos pobres que padecen mucha necesidad y convendría que se les diese algún entretenimiento, más no hay que se les pueda dar, porque toda la hacienda que V.M. aquí tiene se distribuye en salarios y en limosnas de religiosos y en edificios de iglesias y monasterios y en una calzada que se ha hecho en una ciénaga...". ${ }^{5}$

Por otra parte, muchos encomenderos vulneraron las normas dictadas para la concesión de ayudas de costa y se acogieron a las mismas. Recibieron, pues, además de las remuneraciones procedentes de sus repartimientos, las derivadas de las ayudas de costa que les fueron señaladas e impedían que otros vecinos de la provincia, con méritos, pero pobres y sin influencia, percibieran este tipo de ayudas. Rodrigo de Paz, encomendero de Tamulte de la Barranca, Tamulte de la Sabana y Puxcatán, y Antonio de Mayorga, de Soyataco, Chichicapa y Culico ${ }^{86}$ percibieron, durante algunos años, 200 y 150 pesos de oro respectivamente como ayudas de costa que les fueron asignadas por el oidor Loaysa en $1561 .{ }^{87} \mathrm{Sin}$ embargo, se tienen

85 AGI, México, 168, El alcalde mayor de Yucatán, Dr. Diego Quijada, a S.M. dando relación del estado de las cosas en la provincia, Campeche, 20 de mayo 1564.

86 "Relación de la Provincia de Tabasco", en: Relaciones Histórico-Geográficas, vol. II, págs. 373-378.

87 AGI, Justicia, 209, El fiscal de S.M. con los oficiales de la Provincia de Yucatán sobre ciertas adiciones que les fue puestas por el Gobernador de ella de varias ayudas de costa que pagaron, 1567. 
referencias de que muchos pobladores pululaban por la provincia con sus familias, pobres y sin asistencia alguna, verdaderamente necesitados de estas ayudas de costa, como señala el alcalde mayor de Yucatán, Diego de Quijada:

"El tiempo que allí estuve conocí que algunos españoles casados y solteros andaban vagabundos con mujeres e hijos a cuestas, y con su pobreza vivían entre los naturales. Heles mandado recoger en un buen, que está veinte leguas de la villa de la Victoria... Habíanse llegado hasta una docena de vecinos que se humillan a cavar y arar y sustentarse de ello". ${ }^{88}$

Durante el primer cuarto del siglo XVII gran parte de las pensiones o ayudas de costa siguieron percibiéndolas personas que, o bien poseían encomiendas, o cuyos antepasados más cercanos habían tenido cargos de responsabilidad pública en la provincia y en la actualidad no tenían medios de manutención. Este período coincide, como ya se ha referido, entre otras cosas, con el descenso más pronunciado de la población indígena, la consiguiente disminución de tributarios, la progresiva merma de pobladores españoles, la dejación de algunos repartimientos de indios por sus encomenderos y los continuos ataques piráticos que azotaban la costa tabasqueña.

En esta etapa, el acaparamiento de encomiendas por una misma persona empieza a generalizarse. Las especiales condiciones de vida de la provincia, y el descenso de la población española entre ellas, provocaron que muchos encomenderos hicieran dejación de sus repartimientos y éstos, juntos con los que iban quedando vacantes, se concentraran en pocas manos. Sin embargo, existían encomenderos que sólo disponían de una encomienda y no podían vivir o sustentarse de sus tributarios, pues sus rentas eran escasas, una vez pagados el diezmo y la doctrina. Al igual que ocurriera en Yucatán, donde se fue legalizando la costumbre del goce conjunto de encomienda y ayuda de costa, muchas veces con abusos y extralimitaciones, ${ }^{89}$ en Tabasco encontramos este tipo de disfrute. Así, Andrés Rodríguez, en 1605 , y su hijo del mismo nombre, en 1611, vieron confirmadas por la Corona una ayuda de costa cada año de "200 pesos de oro de minas, 200 fanegas de maíz y 200 aves, mitad de la tierra y mitad de Castilla en los tributos que para este efecto se quitaron al adelantado don Francisco de Mon-

88 Carta del Dr. Quijada a S.M. haciendo relación de asuntos pertenecientes a la administración de las provincias de Yucatán y Tabasco, Mérida, 10 de febrero de 1565, en: Scholes y Adams: Don Diego Quijada..., vol. II, págs. 166-181.

89 García Bernal: Población y encomienda..., págs. 315-321. 
tejo y a su mujer e hijos en la dicha provincia de Tabasco". ${ }^{90}$ Pese a ello, seguían existiendo personas que recibían ayudas de costa y no disfrutaban de la concesión de encomiendas, mientras los repartimientos iban progresivamente quedando vacantes y concentrándose en pocas manos.

No todos los beneficiarios de las ayudas de costa eran vecinos de la provincia de Tabasco. Se tiene documentado el caso de Juan Bautista Rejón Arias, vecino de la villa de Mérida, quien en 1604 solicitó al rey la confirmación de una situación de 300 pesos de oro de minas que le fue concedida en 1601 por el gobernador de Yucatán, Diego Fernández de Velasco, en consideración de sus servicios prestados, las necesidades que padecía y no haber recibido con anterioridad otra merced. ${ }^{91}$ En 1605, el mariscal Carlos de Luna Arellano, nuevo gobernador de Yucatán, le señaló a Juan Bautista Rejón 200 ducados de renta en la provincia de Tabasco sobre los tributos procedentes de las encomiendas asignadas en dos mitades a Alonso de Rebolledo y Francisco Ortiz: Tamulte de la Barranca, Tamulte de la Sabana, Oxiacaque, Huaymango, Apazta, Oceloteupa y Ulapa. El resto, pagada la ayuda de costa a Juan Bautista Rejón, "todo lo que valiere y rentare más, se ha de partir entre el dicho Francisco Ortiz y Alonso de Rebolledo". ${ }^{22} \mathrm{Su}$ hija, Andrea Arias Rejón, siguió disfrutando dicha ayuda de costa, aunque rebajada a 100 ducados de Castilla. ${ }^{93}$

$$
* * *
$$

La provincia de Tabasco, y en general todo el sureste novohispano, no era un área donde se podían cumplir las aspiraciones de conquistadores y nuevos pobladores. Muy pronto advirtieron éstos que dichas tierras no guardaban en su seno las ansiadas minas de metales preciosos que terminaran con la indigencia de muchos de ellos. A esta "adversidad" hay que unir el clima y la geografía, que dificultaron el asentamiento de población hispana en el área. Ante esta perspectiva, se ha visto como la encomienda sería la institución desde donde la población benemérita española pudo orientar

90 AGI, México, 133, doc. 3, Ayuda de costa para Andrés Rodríguez por su vida y la de su hijo, Mérida, 1615.

91 AGI, México, 125, doc. 1, Autos de la concesión de ayudas de costa a Juan Bautista Rejón Arias, Mérida, 31 de marzo de 1605,

92 Ibídem.

93 AGI, México, 143, n. ${ }^{\circ}$ 2, doc. 27b, Título de encomienda de Simón Nieto de Salazar, Mérida, 28 de junio de 1622 . 
su actividad y supervivencia en este primer siglo de vida colonial. A través de la encomienda, los conquistadores y primeros pobladores depositaron sus pretensiones, ya fuera por su valor económico como por su atractivo social. En Tabasco, buena parte de sus vecinos eran encomenderos durante el período 1541-1608, lo que les daba fuerza y poder como grupo. A principios del siglo XVII, las especiales condiciones de vida y los descensos demográficos, indígena y español, provocaron que muchos encomenderos hicieran dejación de sus repartimientos y éstos, junto con los que iban quedando vacantes, se concentraran en pocas manos. 